\title{
Microcomputed tomography: approaches and applications in bioengineering
}

\author{
Joel D Boerckel ${ }^{1 *}$, Devon E Mason ${ }^{1}$, Anna M McDermott $^{1}$ and Eben Alsberg ${ }^{2}$
}

\begin{abstract}
Microcomputed tomography (microCT) has become a standard and essential tool for quantifying structurefunction relationships, disease progression, and regeneration in preclinical models and has facilitated numerous scientific and bioengineering advancements over the past 30 years. In this article, we recount the early events that led to the initial development of microCT and review microCT approaches for quantitative evaluation of bone, cartilage, and cardiovascular structures, with applications in fundamental structurefunction analysis, disease, tissue engineering, and numerical modeling. Finally, we address several next-generation approaches under active investigation to improve spatial resolution, acquisition time, tissue contrast, radiation dose, and functional and molecular information.
\end{abstract}

\section{Introduction}

Microcomputed tomography (microCT or $\mu \mathrm{CT}$ ) is a non-destructive imaging tool for the production of highresolution three-dimensional (3D) images composed of two-dimensional (2D) trans-axial projections, or 'slices', of a target specimen. MicroCT equipment is composed of several major components: $\mathrm{x}$-ray tube, radiation filter and collimator (which focuses the beam geometry to either a fan- or cone-beam projection), specimen stand, and phosphor-detector/charge-coupled device camera (Figure 1). Reconstruction of a 3D image is performed by rotating either the sample (for desktop systems) or the emitter and detector (for live animal imaging) to generate a series of $2 \mathrm{D}$ projections that will be transformed to a 3D representation by using a digital process

\footnotetext{
* Correspondence: jboercke@nd.edu

'Department of Aerospace and Mechanical Engineering, Tissue Engineering and Mechanobiology Laboratory, Bioengineering Graduate Program, 142 Multidisciplinary Research Building, University of Notre Dame, Notre Dame, IN 46556, USA

Full list of author information is available at the end of the article
}

called back-projection [1,2]. This non-destructive imaging modality can produce $3 \mathrm{D}$ images and $2 \mathrm{D}$ maps with voxels approaching $1 \mu \mathrm{m}$, giving it superior resolution to other techniques such as ultrasound and magnetic resonance imaging (MRI) [2].

The principle of microCT is based on the attenuation of $\mathrm{x}$-rays passing through the object or sample being imaged. As an $x$-ray passes through tissue, the intensity of the incident $x$-ray beam is diminished according to the equation, $\mathrm{I}_{\mathrm{x}}=\mathrm{I}_{0} \mathrm{e}^{-\mu \mathrm{x}}$, where $\mathrm{I}_{0}$ is the intensity of the incident beam, $x$ is the distance from the source, $I_{x}$ is the intensity of the beam at distance $x$ from the source, and $\mu$ is the linear attenuation coefficient [3]. The attenuation therefore depends on both the sample material and source energy and can be used to quantify the density of the tissues being imaged when the reduced intensity beams are collected by a detector array.

\section{Historical context}

In 1979, Allan Cormack and Godfrey Hounsfield were awarded the Nobel Prize in Physiology or Medicine for the development of computer-assisted tomography and, by the late 1970s, clinical computed tomography (CT) was in widespread use; however, these systems were limited in resolution and yielded only $2 \mathrm{D}$ reconstructions as they relied on line $\mathrm{x}$-rays and linear array detectors. In the early 1980s, Ford Motor Company physicist Lee Feldkamp developed the first microCT system to evaluate structural defects of ceramic automotive materials. Expanding on the concepts of clinical CT systems, Feldkamp conceived of using a cone-beam $\mathrm{x}$-ray source and $2 \mathrm{D}$ detector and rotating the sample itself through $360^{\circ}$. $\mathrm{He}$ then developed the cone-beam algorithm to reconstruct fully 3D images from those projections [4]. A serendipitous meeting between Feldkamp and Michael Kleerekoper of Henry Ford Hospital led to the first scan of bone tissue, an iliac crest biopsy, and resulted in the first public evidence of microCT: an abstract from the 


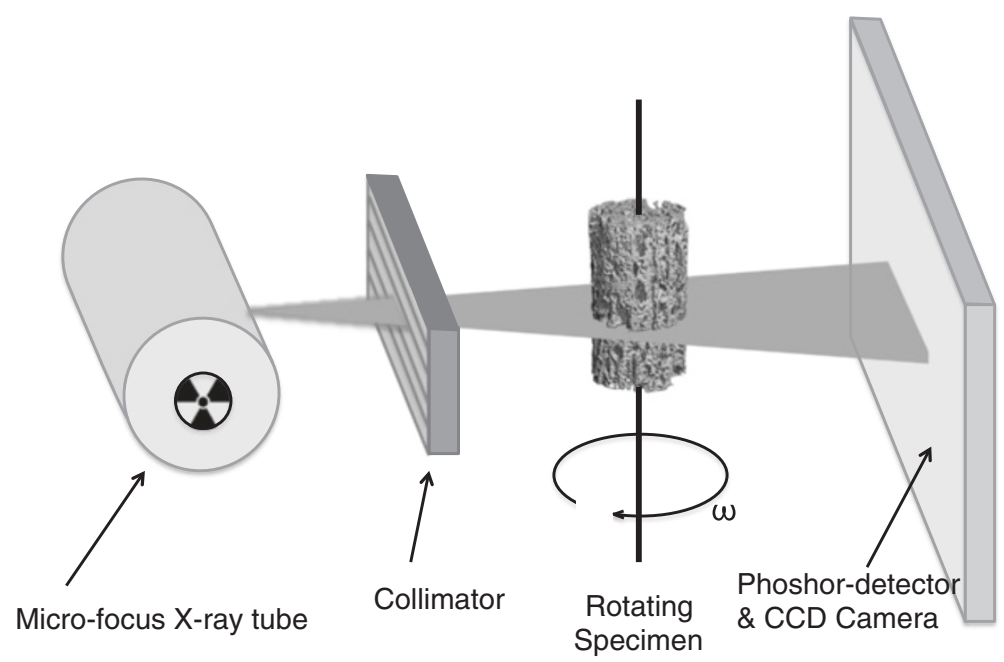

Figure 1 Principal components of a microcomputed tomography scanner. A micro-focus x-ray tube, or synchrotron emitter for monochromatic beam generation, produces radiation, which is collimated and passed through the object. The radiation is attenuated by the sample, and this attenuation is measured by a charge-coupled device (CCD) camera with a phospholayer coating to convert x-rays to visible light. A threedimensional rendering of the sample is achieved by scanning at different angles of rotation and reconstructing through transformation of two-dimensional projections.

1983 meeting of the American Society for Bone and Mineral Research [5].

That same year, through connections at Henry Ford Hospital, Feldkamp was introduced to Steven Goldstein, an orthopedic biomechanician at the University of Michigan. Goldstein would name the technique 'microcomputed tomography', and this collaboration led to the first publication of microCT analysis of bone architecture, an evaluation of subchondral bone in experimental osteoarthritis [6]. This was followed shortly by the now well-known initial trabecular bone microstructure article [7]. In 1984, Goldstein replicated the Feldkamp microCT system in his laboratory, establishing the first university microCT system, and in the ensuing years it became clear that microCT would revolutionize the fields of bone biology and biomechanics. Several commercial microCT systems are now available worldwide, and new innovations continue to expand its speed, resolution, and applicability to non-mineralized tissues.

This review discusses microCT approaches for quantitative evaluation of bone, cartilage, and cardiovascular structures, with applications in fundamental structure-function analysis, disease, tissue engineering, and numerical modeling, and addresses next-generation systems under active investigation and development.

\section{Bone structure, disease, and adaptation}

MicroCT is established as an essential tool for evaluating bone structure and quality and has been used to study metabolic bone diseases such as osteoporosis (Figure 2), to evaluate preclinical models of disease [8], and to test the efficacy of anti-resorptive and anabolic therapeutics, such as bisphosphonates [9]. One emerging technique for microCT-based evaluation of bone fragility induced by loading, aging, or osteoporotic disease is the use of contrast agents to detect and quantify bone microdamage. For example, barium sulfate $\left(\mathrm{BaSO}_{4}\right)$ allows $3 \mathrm{D}$ assessment of exposed calcium to quantify fatigue microdamage in bovine trabecular (Figure 3) [10,11].

MicroCT is now also a standard technique for evaluation of genomic factors on bone phenotype through the use of genomic and tissue-specific knockout mice, as reviewed elsewhere [12,13]. For example, Wang and colleagues [14] used microCT analysis of both bone and vascular structures to show that deletion of von Hippel-Lindau, which regulates expression of the angiogenic growth factor vascular endothelial growth factor through modulating hypoxia-inducible factor (HIF) $1 \alpha$ degradation, resulted in exceedingly dense, highly vascularized long bones, but normal calvariae, whereas the HIF1 $\alpha$ knockouts had the opposite long-bone phenotype. Interestingly, the double knockout exhibited increased long-bone formation and vascularization, enabling identification of a compensatory function of the HIF $2 \alpha$ subunit.

MicroCT imaging affords unique capabilities for nondestructive reconstruction of microstructural features, enabling approaches such as finite element (FE) analysis 

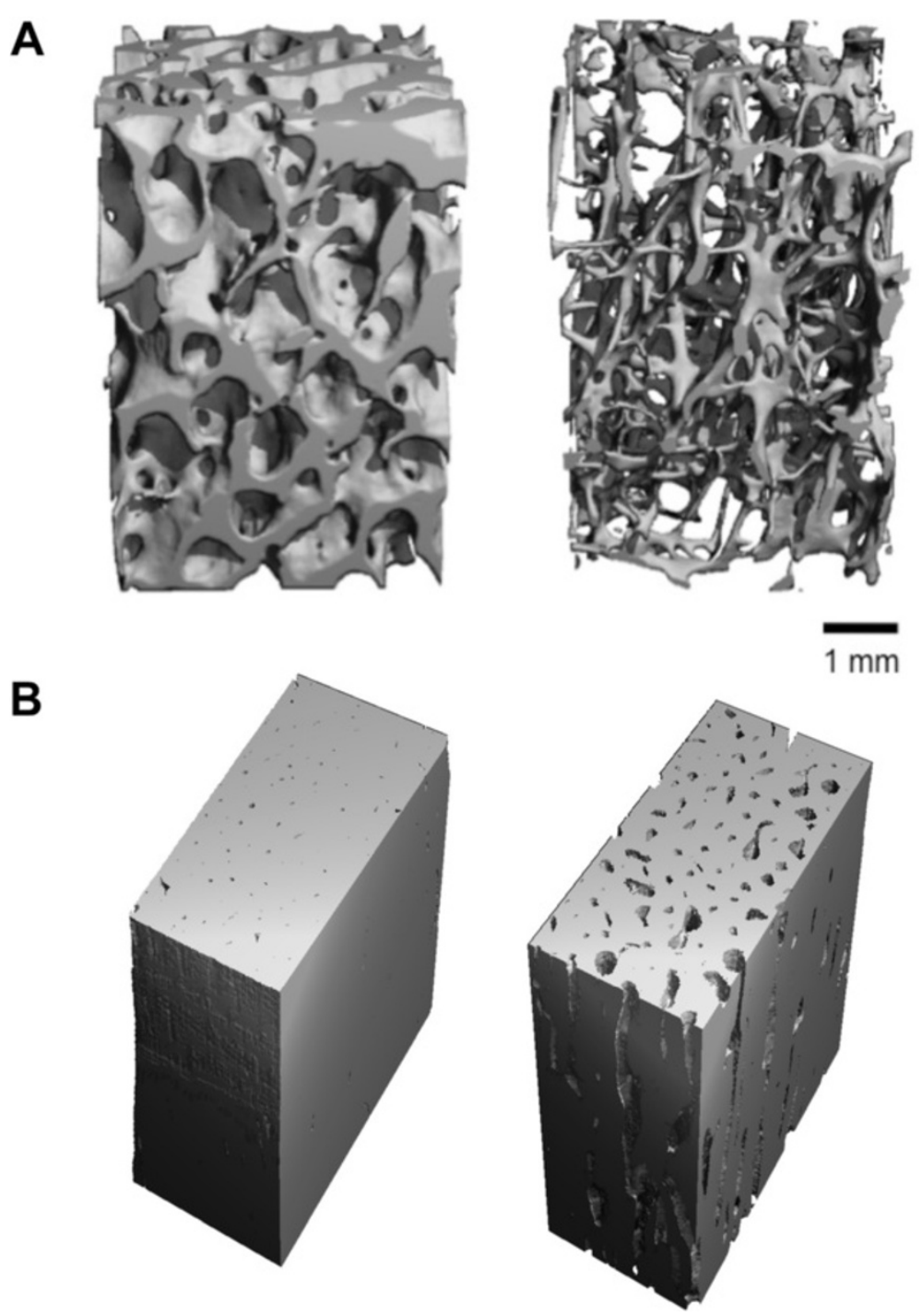

Figure 2 Microcomputed tomography (microCT) reconstruction of cortical and trabecular bone. MicroCT enables high-resolution threedimensional reconstruction of microstructural characteristics from trabecular architecture to cortical porosity. (A) Trabecular bone from femoral neck of 51-year-old male (left) and 84-year-old female (right). (B) Diaphyseal femoral cortical bone of 18-year-old male (left) and 73-year-old female (right). Age, gender, disease, and other factors influence the microstructural properties of both cortical and trabecular bone, and these can be evaluated quantitatively by microct.

to evaluate local biomechanical behavior under complex loading conditions. This method allows virtual recapitulation of experimental or physiologic boundary conditions to estimate local stresses and strains within a tissue of complex geometry [15]. Important considerations for accurate $\mathrm{FE}$ analysis of biological tissues include mesh formulation and resolution, constitutive models that recapitulate salient features of tissue behavior, appropriate boundary conditions, and model size and convergence. Mesh generation may be accomplished either through custom, specimen-specific meshes featuring smooth boundaries and unstructured grids or through direct conversion of digital voxels to hexahedral brick elements. Direct, digital FE models are the easiest to create but may be limited by large model sizes and inaccuracies or instabilities at model or material boundaries, requiring at least four digital FEs through a beam crosssection for accuracy $[16,17]$.

Appropriate constitutive model selection is critical for analysis of biological materials, including bone. Although numerous constitutive formulations have been employed, a universally applicable model has not been identified, and formulation should be carefully considered for each application. For example, some 


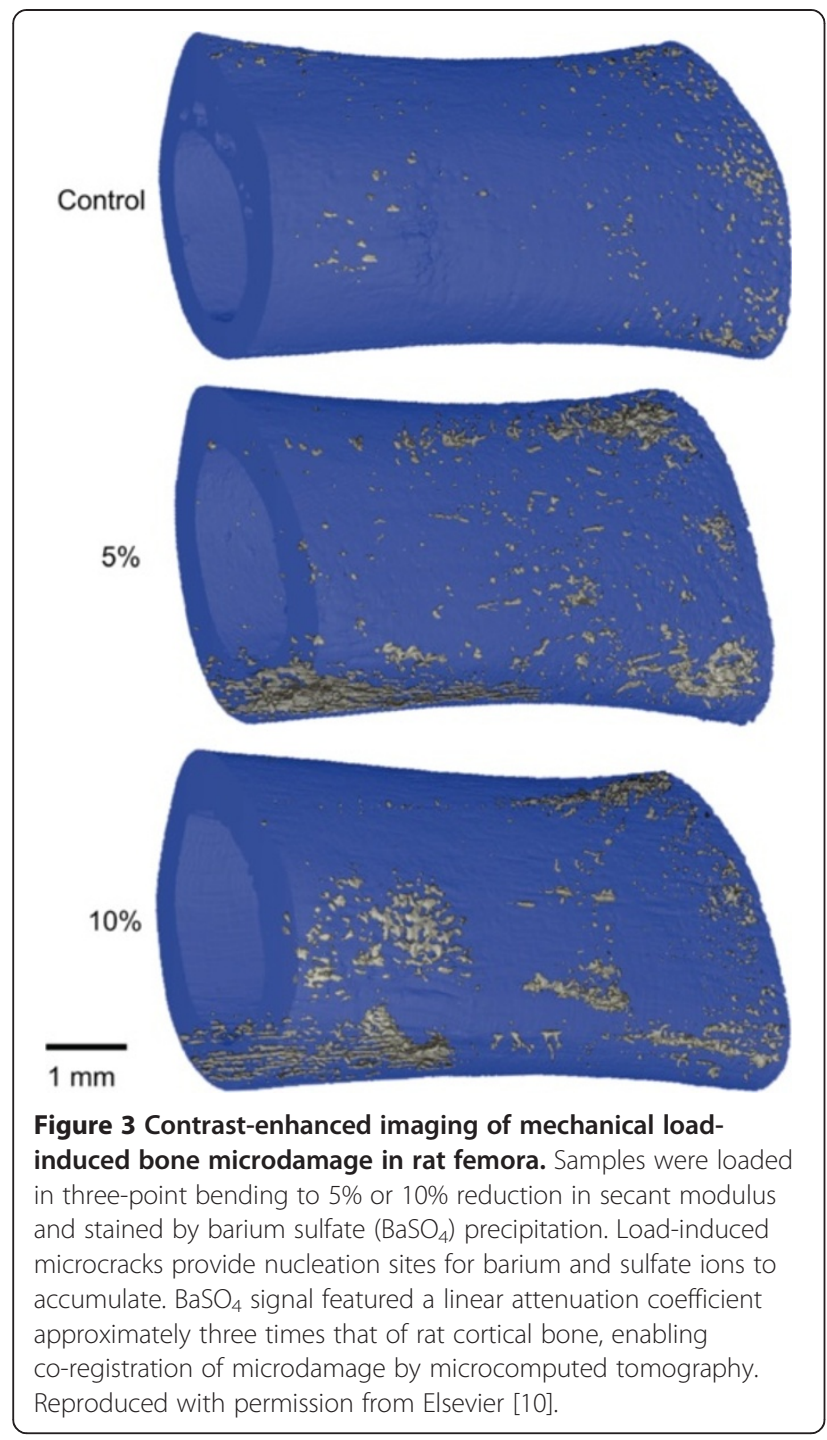

approaches account for inhomogeneity by scaling the local Young's modulus or ultimate stress with microCT-measured local density, either linearly or, more accurately, using a power-law relationship [18-20]. Others have coupled non-linear local constitutive models with microCT-based FE models to predict local plasticity and macroscopic failure of trabecular bone and to relate bone microarchitectural features with apparent-level mechanical behavior [21,22]. Intrinsic mechanical properties can also be validated directly through local measurement by nanoindentation [22] or at the effective level by comparison and scaling with mechanical tests [23]. Finally, accurate physiological boundary conditions are frequently difficult to quantify but may be estimated by inverse dynamics, direct muscle force measurement by electromyography, scaling muscle reaction forces with muscle length or physiological cross-sectional area, or through objective optimization approaches [24].

Current applications of microCT-based FE modeling include evaluation of bone quality, microdamage and failure [25-27], effects of mechanical stimuli on bone regeneration $[23,28,29]$, mechanical regulation of tissue differentiation and remodeling [30-32], and fluid-structure interactions of bone marrow within trabecular bone [33,34]. The non-destructive nature of microCT further makes it ideal for longitudinal evaluation of disuse- and mechanical load-induced bone remodeling and adaptation [35,36]. For example, Müller and colleagues [37-39] have recently published a series of articles using time-lapse in vivo microCT and $\mathrm{FE}$ analysis in a mouse tail vertebra model to longitudinally evaluate the effect of compressive loading or unloading on local bone formation and resorption (Figure 4). Locations of bone formation and resorption correlated with sites of high- and low-strain energy density, respectively, and bone modeling/remodeling did not exhibit a 'lazy zone' as predicted by the long-accepted Frost mechanostat theory [40].

Space limitations prevent comprehensive discussion of the many applications of microCT to bone biomechanics and mechanobiology. We refer interested readers to several excellent focused reviews $[2,41,42]$.

\section{Tissue engineering}

MicroCT emerged as a commercially available tool in the middle of the 'go-go' years of tissue engineering (that is, the 1980s and 1990s) [43], positioning it perfectly for widespread use as the problems targeted by tissue engineers necessitate non-destructive, 3D, quantitative imaging techniques. Tissue engineering approaches have remarkable potential to regenerate damaged and diseased tissues, but increasing evidence highlights the need for control of biomaterial properties to meet the biomechanical and biological requirements of complex tissues and organs. Scaffolds must balance mechanical properties with degradation kinetics and byproducts, sufficient porosity for cellular infiltration and seeding, and drug delivery characteristics, among other criteria [44]. Thus, nondestructive quantification of microstructural characteristics such as porosity, surface-to-volume ratio, interconnectivity, and anisotropy is necessary for scaffold optimization [1,45], and microCT has the potential to provide comprehensive data on these parameters [46].

Scaffold porosity and pore interconnectivity are key factors in biomaterial design to enable cell migration, proliferation, and extracellular matrix production and facilitate tissue in-growth and blood vessel invasion but come with trade-offs in other scaffold parameters, 


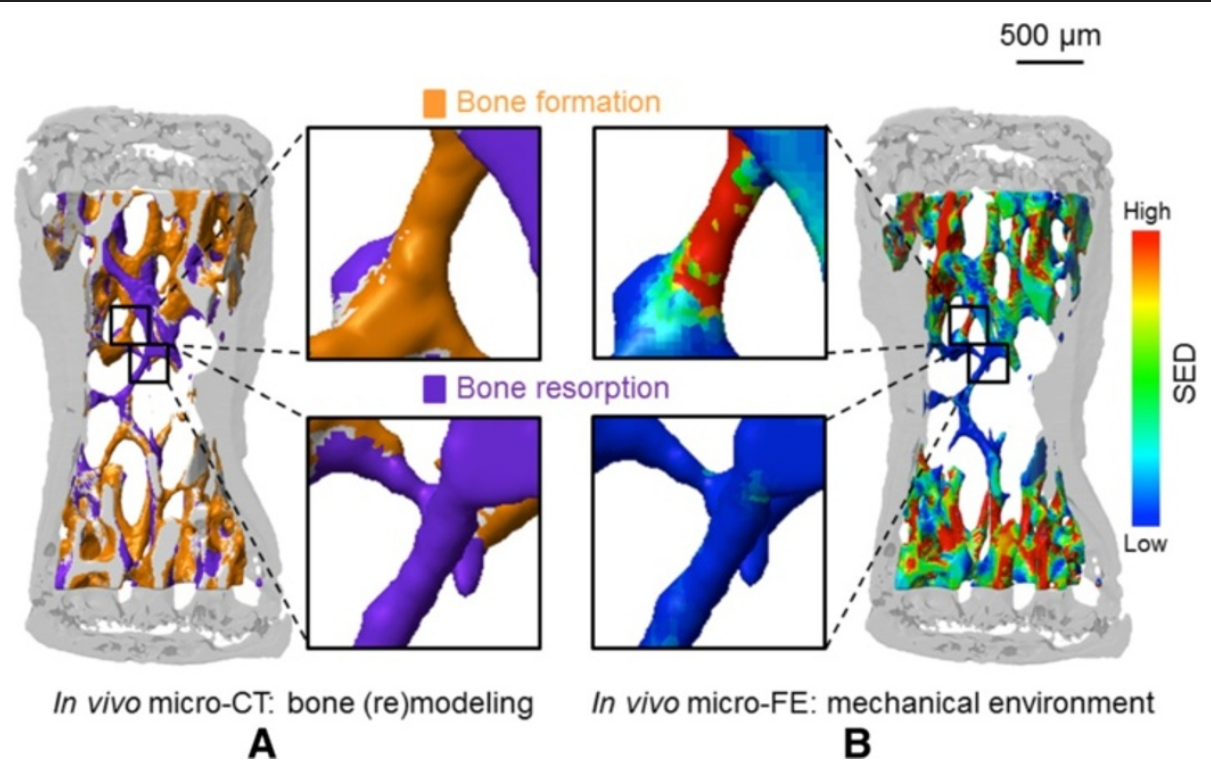

Figure 4 Correlation of local tissue strains with regions of bone formation and resorption by longitudinal in vivo microcomputed tomography (microCT) and finite element (FE) analysis. The sixth caudal vertebra of mice were loaded by pinned compression of the fifth and seventh vertebrae, resulting in a cyclic load of $9 \mathrm{~N}$. Serial, co-registered microCT scans were analyzed to determine locations of bone formation and resorption (A) and correlated with locations of high/low strain energy density (SED) (B), calculated by FE analysis. Bone formation and resorption were significantly more likely in regions of high and low SED, respectively. Reproduced with permission from PLOS [39].

such as mechanical properties [47,48]. For example, Lin and colleagues [49] used microCT to demonstrate the effect of longitudinal macroporosity and porogen concentration on volume fraction, strut density, and anisotropy in oriented porous scaffolds. MicroCT has become a critical tool for quantitative and nondestructive assessment of internal scaffold microstructure to guide scaffold design and manufacture [50-52] and enables non-destructive evaluation of both microstructural and mechanical behavior of multi-phase and fiber-reinforced scaffolds [51,53,54] as well as longitudinal scaffold degradation [55].

MicroCT is also used to evaluate the ability of cellbased tissue engineering bone constructs to form biologic mineralized matrix in vitro [56,57]. These studies and others have demonstrated that osteogenic differentiation of stem cells in vitro is dependent on substrate material and microstructural characteristics [58], cell source (for example, amniotic fluid- versus bone marrow-derived mesenchymal cells) [56], and dimensional (that is, 2D versus 3D) [59] and biomechanical culture conditions [60]. Unlike other in vitro osteogenesis assays, microCT enables longitudinal quantification of the time course of mineralization in 3D without interfering with cell growth or mineral production [57], an important feature for comparison of various cell sources with different mineralization kinetics [56].
In addition to scaffold microstructure, microCT enables assessment of tissue engineered bone formation in animal models [61-65] (for example, high-density stem cell-mediated bone regeneration of calvarial defects) (Figure 5A). To evaluate the importance of porosity and space for tissue regeneration, scaffolds were created as described by Lin and colleagues [49], modified by removal of a $1.5-\mathrm{mm}$ diameter axially oriented cylindrical core (Figure 5B), loaded with $3 \mu \mathrm{g}$ rhBMP-2, and implanted in rat femoral bone defects. Bone formation was localized predominantly to the core space and outer surfaces of the scaffold, indicating a failure of new bone formation to grow into the scaffold itself (Figure 5C), and a hydrogel delivery approach featuring a similar dose of rhBMP$2(2.5 \mu \mathrm{g})$ but without a structural scaffold resulted in greater bone formation, throughout the defect (Figure 5D) [66]. These data suggest that, in spite of high and oriented porosity, structural scaffolds can impede cellular infiltration and tissue regeneration, warranting further research on the role of scaffold porosity and orientation.

Excitingly, multiple companies now provide microCT scanners with a stationary sample container and a rotating gantry housing the $\mathrm{x}$-ray emitter and detector, allowing in vivo imaging of small animals (that is, mice and rats) under anesthesia at resolutions approaching those of standard desktop systems. These 
A

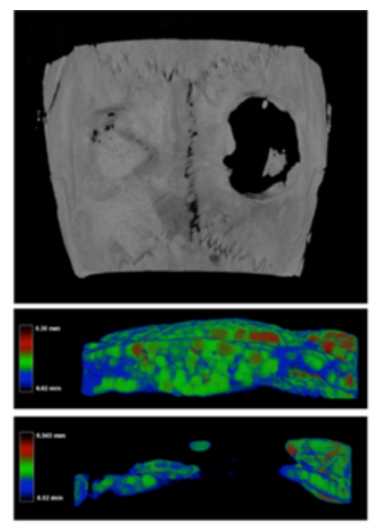

B

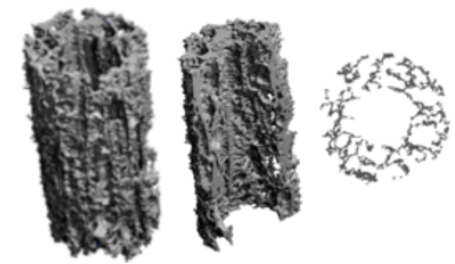

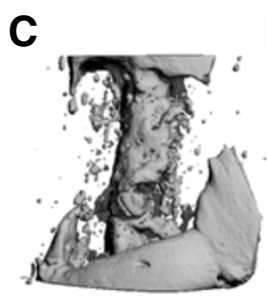

D

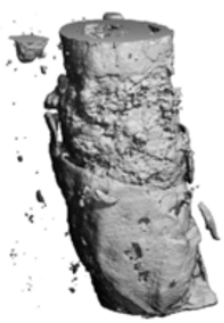

E

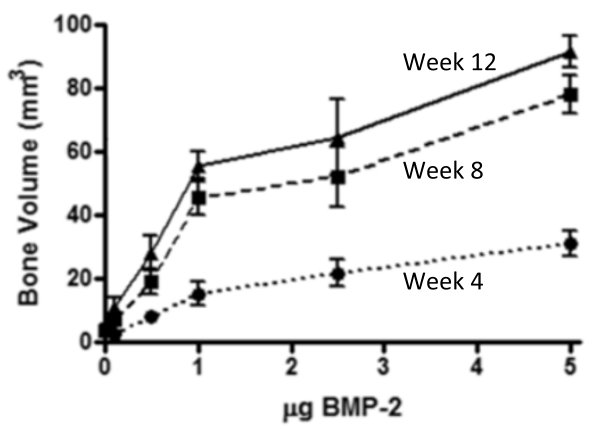

Figure 5 Microcomputed tomography (microCT) analysis of tissue engineering scaffolds and bone regeneration in vivo. (A) MicroCT reconstruction of mesenchymal stem cell-mediated bone regeneration in a bilateral cranial defect model treated with a high-density human mesenchymal stem cell (hMSC) construct incorporating growth factor-loaded microparticles (left) or empty control (right), and sagittal-cut views of three-dimensional thickness mapping overlay of defect regions (Phuong Dang and Eben Aslberg, in preparation). (B) Poly(L/DL)-lactide tri-calcium phosphate (PLDL-TCP) scaffold created according to the protocol of [38] featuring oriented microporosity and central core showing isometric view and transverse cross-section. (C) In vivo bone formation in a rat femoral bone defect model implanted with cored scaffolds from (A) loaded with rhBMP-2 in alginate hydrogel (McDermott and collegues, in preparation) or (D) hydrogel-mediated delivery of rhBMP-2 within a polycaprolactone nanofiber mesh without a structural scaffold in the defect. Reproduced with permission from [49]. (E) In vivo microCT-based longitudinal quantification of bone formation over time (dotted to solid lines) for various doses of BMP-2 in the hybrid nanofiber mesh/alginate delivery system. Reproduced with permission from [49].

systems enable longitudinal quantification of scaffoldintegration and mineralization. For example, Boerckel and colleagues [66] recently evaluated the time course of bone regeneration in a rat segmental bone defect model over 12 weeks to quantify the dynamics of bone formation, mineralization, and maturation (Figure 5E). Important considerations for in vivo microCT imaging include consistent positioning of animals to minimize system variability, volume of interest selection and thresholding to avoid fixation hardware artifacts, and dose of ionizing radiation. As these studies demonstrate, advances in both desktop and in vivo microCT imaging systems will continue to further the field of tissue engineering in years to come.

\section{Vascular imaging}

Evaluation of soft tissues by $\mathrm{x}$-ray imaging requires application of radiodense contrast agents. Contrastenhanced microCT angiography enables visualization of cardiovascular structures, and emerging techniques are enabling this analysis both ex vivo and in vivo.

\section{Ex vivo microcomputed tomography angiography}

The use of microCT to study 3D vascular morphology began with studies of reno-vascular architecture, in which 3D casting of kidney vessels had been a common visualization approach, dating back to the famed British anatomist Sir William Bowman in the mid-19th century [67]. It was therefore a natural progression from polymeric vascular casting combined with interstitial tissue clearing agents (for example, methyl salicylate) [68] to radiodense contrast-agent casting and CT. Highresolution analysis of model animal vascular structures by microCT was first conducted on renal microvasculature in 1998 [69]. Today, ex vivo microCT angiography is a powerful tool for 3D high-resolution evaluation of post-natal vascular growth in models of tissue ischemia (Figure 6) [70,71], tissue engineering (Figure 7) [28,72], and tumor angiogenesis [73,74]. Owing to the small size of arteriole and venule microvasculature and the difficulty of efficient perfusion of potentially leaky vessels in certain animal models, several variables must be considered depending on application, including contrast-agent properties such as radiodensity and viscosity, scanning 
A

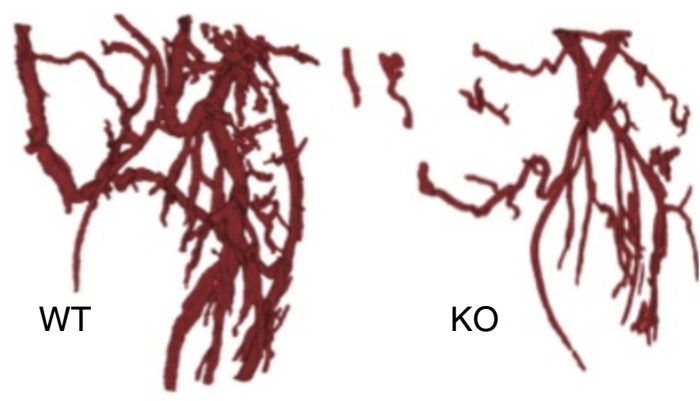

B

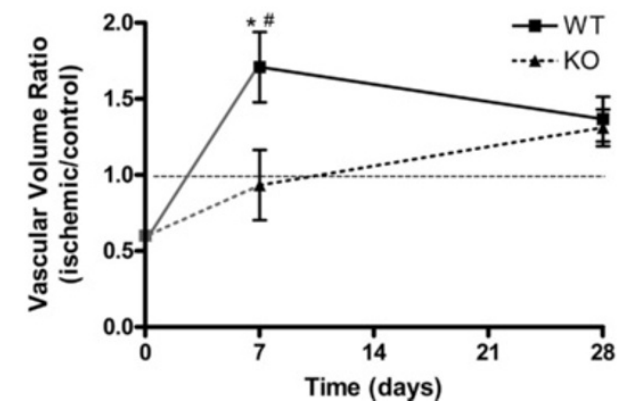

Figure 6 Microcomputed tomography angiography analysis of hindlimb ischemia recovery. (A) Three-dimensional reconstructions of distal hindlimb vasculature in wild-type (WT) (left) and MKP-1 knockout (KO) (right) mice at day 7 post-surgery. Reproduced with permission from the American Heart Association [71]. (B) Quantification of vascular volume ratio (ischemic/contralateral control), illustrating the biphasic nature of angiogenic and arteriogenic vascular recovery. Initial conditions $\left(T_{0}\right)$ taken from comparable WT C57Bl6 mice in [75], with continuity indicated by gray lines. Horizontal line illustrates ischemic/ control ratio of 1 .

resolution, threshold and segmentation approaches, and output parameters. Common vascular contrast agents include microfil MV-122 and BaSO4/gelatin. Many of these variables have been systematically addressed in a hindlimb ischemia model [70].

Ex vivo microCT angiography has enabled novel observations of fundamental biological processes. For example, serial perfusion and microCT scanning [75] has demonstrated that the process of recovery from hindlimb ischemia is analogous to the response profile of an under-damped feedback control system, with a biphasic recovery featuring an early vessel growth phase resulting in vascular parameters exceeding those of native vessel architecture and a later remodeling phase of vascular rarefaction and remodeling back to normal parameters [71,75] (Figure 6A). A further advantage of microCT is the ability to separate 3D regions of interest, enabling independent analysis of the upper hindlimb, where arteriogenesis dominates vascular recovery, and the distal hindlimb, where angiogenesis dominates [71]. This approach is limited by resolution, with voxel sizes typically around $20 \mu \mathrm{m}$. As capillary beds have vessel diameters of 5 to $10 \mu \mathrm{m}$, many vessels will be missed or registered as only partial volumes; therefore, care must be taken during interpretation regarding the detailed processes of angiogenesis and arteriogenesis, and these larger-scale measurements should be confirmed by immunohistochemical analysis on the microvascular scale.

In the context of bone/vascular interactions, the overlap in attenuation coefficients for bone and vascular contrast agents enables simultaneous segmentation of bone and vascular structures (Figure 7A,B) but requires decalcification and volume subtraction for separate quantification (Figure 7D) and precludes bone microstructural analyses (for example, connectivity and density) other than volume [28]. Development of novel contrast agents with non-overlapping attenuation histograms or application of next-generation microCT approaches (for example, spectral CT) would enable simultaneous segmentation of bone and vascularity without decalcification.

\section{In vivo microcomputed tomography angiography}

Recent advances in intravenous microCT contrast agents and cardiac and respiratory gating strategies have enabled in vivo microCT imaging of cardiac and vascular structures, albeit with reduced contrast, resolution, and quantitative functionality compared to ex vivo microCT angiography [76,77]. Briefly, in vivo microCT angiography can be performed by using iodinated monomer-based bolus (for example, iomeprol) or lipid immulsion-based blood-pool (for example, Fenestra VC, MediLumine Inc., Montreal, QC, Canada) contrast agents [76]. Owing to the short cardiac cycle and rapid respiration rate of small rodents, gating strategies (either prospective or retrospective) are required to minimize motion artifacts. In prospective gating, acquisition of images is initiated in response to a physiological signal (for example, electrocardiography); in retrospective gating, physiological signals are recorded at the same time as image data to be sorted later [78]. Prospective gating can have long acquisition time but wide-angular distribution, whereas retrospective gating is characterized by fast scanning and irregular angular distribution [76]. Developing new approaches to achieve high-quality, quantitative in vivo microCT imaging remains an active area of research, and the most successful to date have relied on custom microCT or volumetric $\mathrm{CT}$ systems capable of rapid scan times and high resolution $[76,77]$.

\section{Contrast-enhanced cartilage imaging}

Recently, a radiopaque contrast agent has been developed to enable microCT imaging of non-mineralized 
A

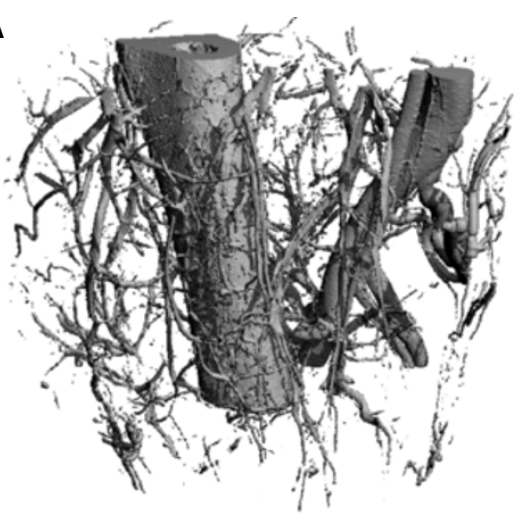

C

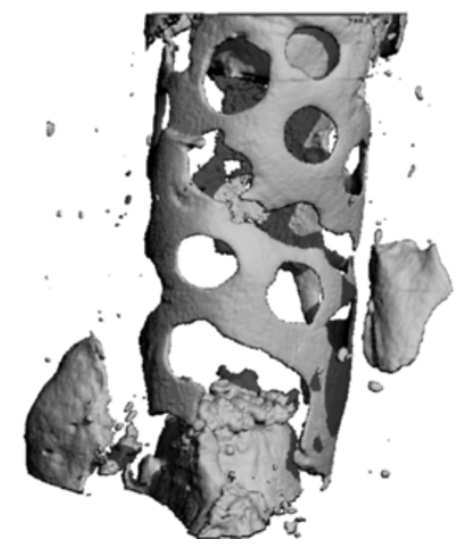

B

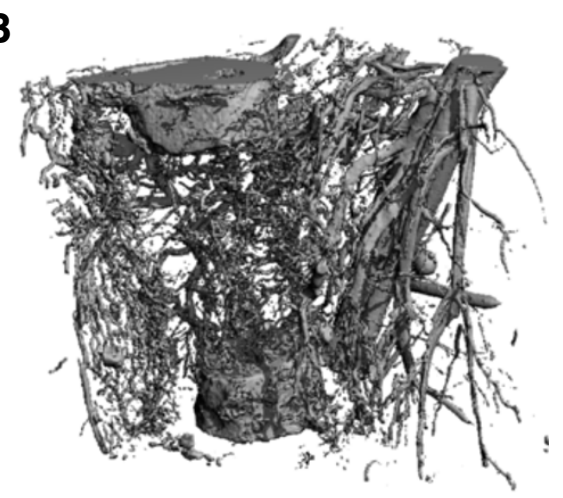

D

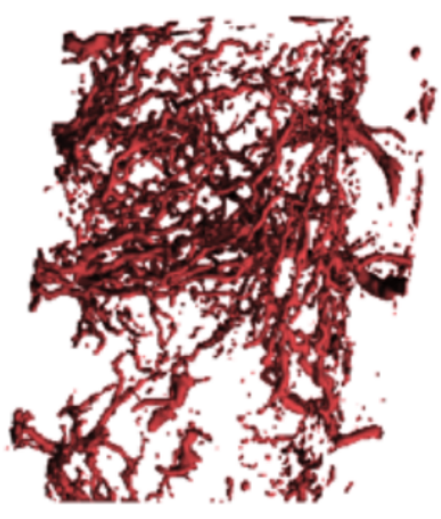

Figure 7 Microcomputed tomography (microCT) angiography of vascular response to bone injury and regeneration. (A) MicroCT image of age-matched unoperated rat femur with surrounding vasculature: the large vessels on the right-hand side are the femoral artery and vein. (B) Vascular structures and bone ends 3 weeks after creation of an 8-mm bone defect. There is a robust neovascular response to bone injury, characterized by increased branching, new vessel formation, and decreased degree of vascular anisotropy. (C) MicroCT image of a nanofiber mesh wrapped around a bone defect. Bone formation has occurred on the surface of the mesh, highlighting the mesh perforations. (D) MicroCT angiography was used to visualize radially directed vascular ingrowth from the surrounding soft tissue envelope through the nanofiber mesh perforations, illustrating the contribution of soft tissues to regenerate bone vascularization and the importance of biomaterial porosity. Owing to the overlapping attenuation of bone and the lead chromate contrast agent, separate segmentation within the same sample is not possible without extensive post-processing and image registration. Images reproduced with permission from the National Academy of Sciences [28] (frames A and B) and from Elsevier [66] (frames C and D).

cartilage by taking advantage of the charged nature of normal cartilage extracellular matrix. Healthy articular cartilage contains a large amount of negatively charged sulfated glycosaminoglycans (sGAG) such as aggrecan, whereas the interstitial fluid carries positively charged solutes, resulting in net electroneutrality [79]. However, the early stages of osteoarthritis are characterized by a cleavage of these proteoglycans, resulting in reduced sGAG content in the diseased tissue. Palmer and colleagues [79] developed a technique called equilibrium partitioning of ionic contrast agent via microCT (EPIC-microCT), in which the tissue is equilibrated with the radiopaque, negatively charged contrast agent, hexabrix (ioxaglate), which is distributed inversely to the fixed negative charges on the proteoglycan matrix, enabling simultaneous, nondestructive microCT evaluation of both cartilage morphology and composition (Figure 8) [80]. This technique has been applied to evaluate numerous normal and osteoarthritic disease models, including rabbit [79], rat [81,82], mouse [83], dog [84], and goat [85] as well as human cadaveric cartilage [86]. EPICmicroCT has also been used to non-invasively image cartilage degeneration longitudinally in vivo $[87,88]$, although challenges associated with contrast agent leakage and equilibration time remain. In summary, this technique promises to become a standard in animal model studies of osteoarthritis as it is nondestructive and provides quantitative morphological and compositional outcomes. 


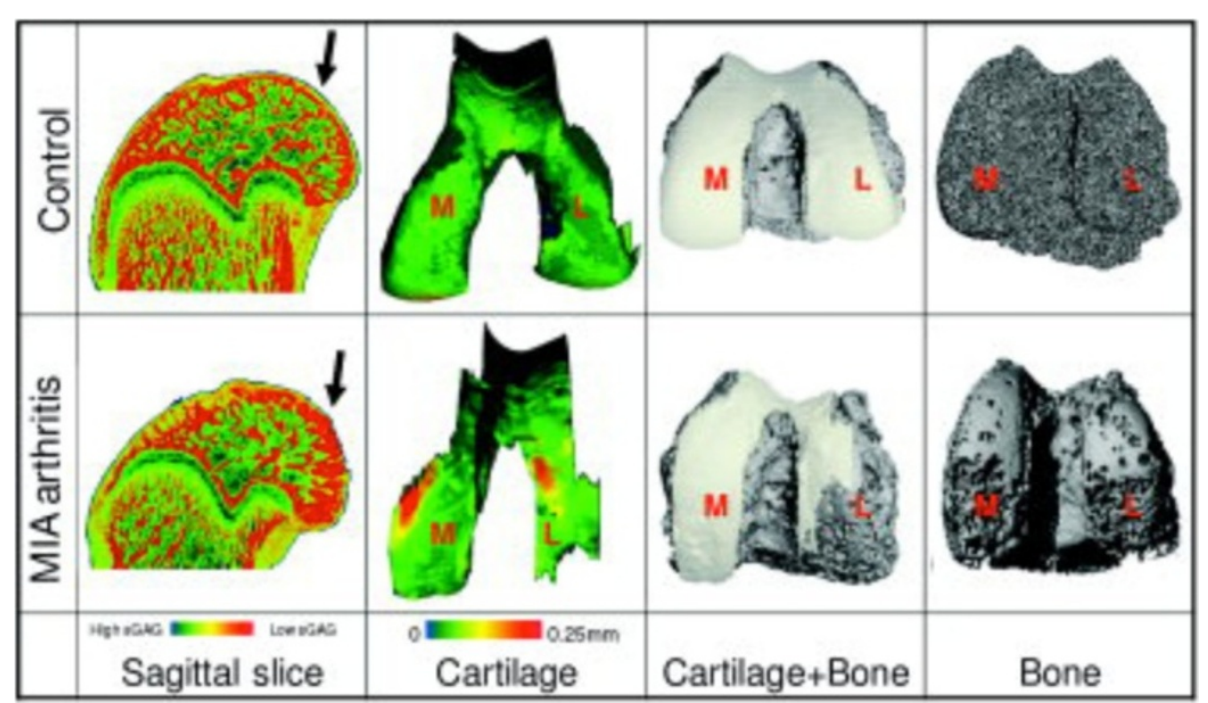

Figure 8 Equilibrium partitioning by ionic contrast-agent microcomputed tomography (EPIC-microCT). Experimental osteoarthritis was induced by intra-synovial injection of monosodium iodoacetate (MIA) and evaluated at week 3 by EPIC-microCT. Excised rat femurs were equilibrated with an ionic contrast agent (hexabrix) and scanned to assess cartilage and subchondral bone. The arthritic group exhibited substantial sulfated glycosaminoglycan depletion, cartilage degradation, and subchondral bone resorption, illustrating the capacity of contrast-enhanced microCT to quantitatively assess cartilage and bone in preclinical models of osteoarthritis. Arrows indicate location of complete cartilage degradation in MIA group and corresponding location in the control. L, lateral; M, medial. Figure reproduced with permission from John Wiley \& Sons, Inc. [80].

\section{Next-generation approaches}

Advanced, composite, and next-generation microCT imaging modalities are an active area of research. One rapidly emerging technique that takes advantage of $x$-ray intensity spectra instead of integrating attenuation over the entire spectrum is spectral microCT [89]. The theoretic framework for spectral CT was established by Alvarez and Macovski in 1976, when they demonstrated that dual-energy $x$-ray imaging enables deconvolution of the effects of Compton and photoelectric scattering, the two interactions that contribute to the linear attenuation coefficient [90]. Thus, precise local density mapping can be accurately quantified $[90,91]$. This approach further yields 3D information on atomic composition and electron density [92], enables discrimination between materials that would have the same attenuation in standard microCT $[89,93]$, and dramatically expands the supply of contrast agents [93].

A second, rapidly evolving experimental microCT imaging technique is phase-contrast microCT. This powerful imaging modality bases image detection on the phase shift of refracted $x$-rays rather than intensity attenuation and promises increased tissue contrast and greater resolution for even soft tissues without the need for contrast agents [94,95]. For most biological materials, the phase shift of the incident $x$-ray is proportional to the sample mass density, enabling high-contrast imaging of both soft and hard tissues by microCT [95]. Recently, Tapfer and colleagues, in collaboration with Bruker ${ }^{\circ}$ MicroCT (Bruker Corporation, Billerica, MA, USA), described a rotating gantry phase-contrast microCT system based on a polychromatic x-ray source [96] that they have applied to ex vivo scans of a murine pancreatic tumor model with soft tissue contrast similar to MRI [97]. It is likely that in vivo phasecontrast microCT imaging for small-animal models will be established in the coming years, which will represent a great advance in microCT imaging capabilities.

\section{Conclusions}

MicroCT has contributed to dramatic advances in biology and bioengineering over the past 30 years, enabling fundamental studies in bone structure and function, quantitative evaluation of disease progression and treatment, development of new tissue engineering strategies, and contrast-enhanced soft tissue imaging. Both desktop and in vivo microCT systems are increasing in availability and application, and continued advancements and innovations promise to continue this trajectory into the future. 
Note: This article is part of a thematic series on Functional imaging in regenerative medicine. Other articles in the series can be found online at http://stemcellres.com/series/FIRM.

\section{Abbreviations \\ 2D: Two-dimensional; 3D: Three-dimensional; $\mathrm{BaSO}_{4}$ : Barium sulfate; CT: Computed tomography; EPIC-microCT: Equilibrium partitioning of ionic contrast agent via microcomputed tomography; FE: Finite element; HIF: Hypoxia-inducible factor; microCT: Microcomputed tomography; MRI: Magnetic resonance imaging; sGAG: Sulfated glycosaminoglycans.}

\section{Competing interests}

The authors declare that they have no competing interests.

\section{Acknowledgments}

The authors thank Steven Goldstein of the University of Michigan for helpfu discussions and descriptions of events surrounding the invention and early implementation of microCT.

\section{Author details}

${ }^{1}$ Department of Aerospace and Mechanical Engineering, Tissue Engineering and Mechanobiology Laboratory, Bioengineering Graduate Program, 142 Multidisciplinary Research Building, University of Notre Dame, Notre Dame, IN 46556, USA. ${ }^{2}$ Department of Biomedical Engineering, Wickenden Bldg, Room 204, 10900 Euclid Ave, Cleveland, OH 44106, USA.

\section{Published: 29 December 2014}

\section{References}

1. Guldberg RE, Ballock RT, Boyan BD, Duvall CL, Lin ASP, Nagaraja S, Oest M, Phillips J, Porter BD, Robertson G, Taylor WR. Analyzing bone, blood vessels, and biomaterials with microcomputed tomography. IEEE Eng Med Biol Mag. 2003; 22:77-83.

2. Müller R. Hierarchical microimaging of bone structure and function. Nat Rev Rheumatol. 2009; 5:373-81.

3. Stauber M, Müller R. Micro-computed tomography: a method for the non-destructive evaluation of the three-dimensional structure of biological specimens. Methods Mol Biol. 2008; 455:273-92.

4. Feldkamp LA, Davis LC, Kress JW. Practical cone-beam algorithm. J Opt Soc Am A. 1984; 1:612-9.

5. Feldkamp LA, Kleerekoper M, Kress JW, Freeling R, Mathews CH, Parfitt AM. Investigation of three-dimensional structure of trabecular bone by computed tomography of iliac biopsy samples [abstract]. Calcif Tissue Int. 1983; 35:669.

6. Layton MW, Goldstein SA, Goulet RW, Feldkamp LA, Kubinski DJ, Bole GG Examination of subchondral bone architecture in experimental osteoarthritis by microscopic computed axial tomography. Arthritis Rheum. 1988; 31:1400-5.

7. Feldkamp LA, Goldstein SA, Parfitt AM, Jesion G, Kleerekoper M. The direct examination of three-dimensional bone architecture in vitro by computed tomography. J Bone Miner Res. 1989; 4:3-11.

8. Ito M, Nishida A, Nakamura T, Uetani M, Hayashi K. Differences of threedimensional trabecular microstructure in osteopenic rat models caused by ovariectomy and neurectomy. Bone. 2002; 30:594-8.

9. O'Neal JM, Diab T, Allen MR, Vidakovic B, Burr DB, Guldberg RE. One year of alendronate treatment lowers microstructural stresses associated with trabecular microdamage initiation. Bone. 2010; 47:241-7.

10. Turnbull TL, Gargac JA, Niebur GL, Roeder RK. Detection of fatigue microdamage in whole rat femora using contrast-enhanced microcomputed tomography. J Biomech. 2011; 44:2395-400.

11. Landrigan MD, Li J, Turnbull TL, Burr DB, Niebur GL, Roeder RK. Contrastenhanced micro-computed tomography of fatigue microdamage accumulation in human cortical bone. Bone. 2011; 48:443-50.

12. Gregg $\mathrm{CL}$, Butcher JT. Quantitative in vivo imaging of embryonic development: opportunities and challenges. Differentiation. 2012; 84:149-62.

13. Guldberg RE, Lin ASP, Coleman R, Robertson G, Duvall C. Microcomputed tomography imaging of skeletal development and growth. Birth Defects Res C Embryo Today. 2004; 72:250-9.
14. Wang $Y$, Wan C, Deng L, Liu X, Cao X, Gilbert SR, Bouxsein ML, Faugere M, Guldberg RE, Gerstenfeld LC, Haase VH, Johnson RS, Schipani E, Clemens TL. The hypoxia-inducible factor a pathway couples angiogenesis to osteogenesis during skeletal development. J Clin Invest. 2007; 117:1616-26.

15. Van Rietbergen $B$, Weinans $H$, Huiskes $R$, Odgaard A. A new method to determine trabecular bone elastic properties and loading using micromechanical finite-element models. J Biomech. 1995; 28:69-81.

16. Guldberg RE, Hollister SJ, Charras GT. The accuracy of digital image-based finite element models. J Biomech Eng. 1998; 120:289-95.

17. Niebur GL, Yuen JC, Hsia AC, Keaveny TM. Convergence behavior of highresolution finite element models of trabecular bone. J Biomech Eng. 1999; 121:629-35.

18. Morgan EF, Bayraktar HH, Keaveny TM. Trabecular bone modulus-density relationships depend on anatomic site. J Biomech. 2003; 36:897-904.

19. Keller TS. Predicting the compressive mechanical behavior of bone. J Biomech. 1994; 27:1159-68.

20. Keyak JH, Rossi SA, Jones KA, Skinner HB. Prediction of femoral fracture load using automated finite element modeling. J Biomech. 1998; 31:125-33.

21. Verhulp E, van Rietbergen B, Müller R, Huiskes R. Indirect determination of trabecular bone effective tissue failure properties using micro-finite element simulations. J Biomech. 2008; 41:1479-85.

22. Harrison NM, McHugh PE. Comparison of trabecular bone behavior in core and whole bone samples using high-resolution modeling of a vertebral body. Biomech Model Mechanobiol. 2010; 9:469-80.

23. Boerckel JD, Kolambkar YM, Stevens HY, Lin AS, Dupont KM, Guldberg RE. Effects of in vivo mechanical loading on large bone defect regeneration. J Orthop Res. 2012; 30:1067-75.

24. Erdemir A, McLean S, Herzog W, van den Bogert AJ. Model-based estimation of muscle forces exerted during movements. Clin Biomech. 2007;22:131-54

25. Nagaraja S, Skrinjar O, Guldberg RE. Spatial correlations of trabecular bone microdamage with local stresses and strains using rigid image registration. J Biomech Eng. 2011; 133:064502.

26. Green JO, Diab T, Allen MR, Vidakovic B, Burr DB, Guldberg RE. Three years of alendronate treatment does not continue to decrease microstructural stresses and strains associated with trabecular microdamage initiation beyond those at 1 year. Osteoporos Int. 2012; 23:2313-20.

27. Gargac JA, Turnbull TL, Roeder RK, Niebur GL. A probabilistic damage model based on direct 3-D correlation of strain to damage formation following fatigue loading of rat femora. J Mech Behav Biomed Mater. 2014; 30:234-43.

28. Boerckel JD, Uhrig BA, Willett NJ, Huebsch N, Guldberg RE. Mechanical regulation of vascular growth and tissue regeneration in vivo. Proc Natl Acad Sci U S A. 2011; 108:E674-80.

29. Mehta M, Checa S, Lienau J, Hutmacher D, Duda GN. In vivo tracking of segmental bone defect healing reveals that callus patterning is related to early mechanical stimuli. Eur Cell Mater. 2012; 24:358-71. discussion 371.

30. Byrne DP, Lacroix D, Prendergast PJ. Simulation of fracture healing in the tibia: mechanoregulation of cell activity using a lattice modeling approach. J Orthop Res. 2011; 29:1496-503.

31. Hayward LN, Morgan EF. Assessment of a mechano-regulation theory of skeletal tissue differentiation in an in vivo model of mechanically induced cartilage formation. Biomech Model Mechanobiol. 2009; 8:447-55.

32. Isaksson H, Gröngröft I, Wilson W, van Donkelaar CC, van Rietbergen B, Tami A, Huiskes $R$, Ito K. Remodeling of fracture callus in mice is consistent with mechanical loading and bone remodeling theory. J Orthop Res. 2009; 27:664-72.

33. Birmingham E, Kreipke TC, Dolan EB, Coughlin TR, Owens P, McNamara LM, Niebur GL, McHugh PE. Mechanical stimulation of bone marrow in situ induces bone formation in trabecular explants. Ann Biomed Eng. 2014 [Epub ahead of print].

34. Coughlin TR, Niebur GL. Fluid shear stress in trabecular bone marrow due to low-magnitude high-frequency vibration. J Biomech. 2012; 45:2222-9.

35. Robling AG, Hinant FM, Burr DB, Turner $\mathrm{CH}$. Improved bone structure and strength after long-term mechanical loading is greatest if loading is separated into short bouts. J Bone Miner Res. 2002; 17:1545-54.

36. Sugiyama T, Meakin LB, Browne WJ, Galea GL, Price JS, Lanyon LE. Bones' adaptive response to mechanical loading is essentially linear between the low strains associated with disuse and the high strains associated with the lamellar/woven bone transition. J Bone Miner Res. 2012; 27:1784-93.

37. Schulte FA, Lambers FM, Kuhn G, Müller R. In vivo micro-computed tomography allows direct three-dimensional quantification of both bone formation and bone resorption parameters using time-lapsed imaging. Bone. 2011; 48:433-42. 
38. Lukas C, Ruffoni D, Lambers FM, Schulte FA, Kuhn G, Kollmannsberger $P$, Weinkamer R, Müller R. Mineralization kinetics in murine trabecular bone quantified by time-lapsed in vivo micro-computed tomography. Bone. 2013; 56:55-60.

39. Schulte FA, Ruffoni D, Lambers FM, Christen D, Webster DJ, Kuhn G, Müller R. Local mechanical stimuli regulate bone formation and resorption in mice at the tissue level. PLoS One. 2013; 8:e62172.

40. Frost HM. Bone's mechanostat: a 2003 update. Anat Rec A Discov Mol Cell Evol Biol. 2003; 275:1081-101.

41. Bouxsein ML, Boyd SK, Christiansen BA, Guldberg RE, Jepsen KJ, Müller R. Guidelines for assessment of bone microstructure in rodents using micro-computed tomography. J Bone Miner Res. 2010; 25:1468-86.

42. Van Rietbergen B. Micro-FE analyses of bone: state of the art. Adv Exp Med Biol. 2001; 496:21-30

43. Badylak SF, Nerem RM. Progress in tissue engineering and regenerative medicine. Proc Natl Acad Sci U S A. 2010; 107:3285-6.

44. Lin CY, Kikuchi N, Hollister SJ. A novel method for biomaterial scaffold internal architecture design to match bone elastic properties with desired porosity. J Biomech. 2004; 37:623-36.

45. Murphy WL, Dennis RG, Kileny JL, Mooney DJ. Salt fusion: an approach to improve pore interconnectivity within tissue engineering scaffolds. Tissue Eng. 2002; 8:43-52

46. Ho ST, Hutmacher DW. A comparison of micro CT with other techniques used in the characterization of scaffolds. Biomaterials. 2006; 27:1362-76.

47. Freed LE, Vunjak-Novakovic G, Biron RJ, Eagles DB, Lesnoy DC, Barlow SK, Langer R. Biodegradable polymer scaffolds for tissue engineering. Biotechnology (N Y). 1994; 12:689-93.

48. Kim J, Li WA, Sands W, Mooney DJ. Effect of pore structure of macroporous poly(lactide-co-glycolide) scaffolds on the in vivo enrichment of dendritic cells. ACS Appl Mater Interfaces. 2014; 6:8505-12.

49. Lin ASP, Barrows TH, Cartmell SH, Guldberg RE. Microarchitectural and mechanical characterization of oriented porous polymer scaffolds. Biomaterials. 2003; 24:481-9.

50. Williams JM, Adewunmi A, Schek RM, Flanagan CL, Krebsbach PH, Feinberg SE, Hollister SJ, Das S. Bone tissue engineering using polycaprolactone scaffolds fabricated via selective laser sintering. Biomaterials. 2005; 26:4817-27.

51. Lohfeld S, Cahill S, Barron V, McHugh P, Dürselen L, Kreja L, Bausewein C, Ignatius A. Fabrication, mechanical and in vivo performance of polycaprolactone/tricalcium phosphate composite scaffolds. Acta Biomater. 2012; 8:3446-56.

52. Saito E, Suarez-Gonzalez D, Rao RR, Stegemann JP, Murphy WL, Hollister SJ. Use of micro-computed tomography to nondestructively characterize biomineral coatings on solid freeform fabricated poly (L-lactic acid) and poly (( $\varepsilon$-caprolactone) scaffolds in vitro and in vivo. Tissue Eng Part C Methods. 2013; 19:507-17.

53. Converse GL, Conrad TL, Merrill CH, Roeder RK. Hydroxyapatite whiskerreinforced polyetherketoneketone bone ingrowth scaffolds. Acta Biomater. 2010; 6:856-63.

54. Doyle $\mathrm{H}$, Lohfeld $\mathrm{S}, \mathrm{McHugh}$ P. Predicting the elastic properties of selective laser sintered PCL/ $\beta$-TCP bone scaffold materials using computational modelling. Ann Biomed Eng. 2014; 42:661-77.

55. Behravesh E, Timmer MD, Lemoine JJ, Liebschner MA, Mikos AG. Evaluation of the in vitro degradation of macroporous hydrogels using gravimetry, confined compression testing, and microcomputed tomography. Biomacromolecules. 2002; 3:1263-70.

56. Peister A, Woodruff MA, Prince JJ, Gray DP, Hutmacher DW, Guldberg RE. Cell sourcing for bone tissue engineering: amniotic fluid stem cells have a delayed, robust differentiation compared to mesenchymal stem cells. Stem Cell Res. 2011; 7:17-27.

57. Thimm BW, Wechsler O, Bohner M, Müller R, Hofmann S. In vitro ceramic scaffold mineralization: comparison between histological and micro-computed tomographical analysis. Ann Biomed Eng. 2013; 41:2666-75.

58. Peister A, Deutsch ER, Kolambkar Y, Hutmacher DW, Guldberg RE. Amniotic fluid stem cells produce robust mineral deposits on biodegradable scaffolds. Tissue Eng Part A. 2009; 15:3129-38.

59. Shen FH, Werner BC, Liang H, Shang H, Yang N, Li X, Shimer AL, Balian G, Katz AJ. Implications of adipose-derived stromal cells in a 3D culture system for osteogenic differentiation: an in vitro and in vivo investigation. Spine J. 2013; 13:32-43.
60. Zhang ZY, Teoh SH, Teo EY, Khoon Chong MS, Shin CW, Tien FT, Choolani MA, Chan JK. A comparison of bioreactors for culture of fetal mesenchymal stem cells for bone tissue engineering. Biomaterials. 2010; 31:8684-95.

61. Kempen DH, Yaszemski MJ, Heijink A, Hefferan TE, Creemers LB, Britson J, Maran A, Classic KL, Dhert WJ, Lu L. Non-invasive monitoring of BMP-2 retention and bone formation in composites for bone tissue engineering using SPECT/CT and scintillation probes. J Control Release. 2009; 134:169-76.

62. Kolambkar YM, Dupont KM, Boerckel JD, Huebsch N, Mooney DJ, Hutmacher DW, Guldberg RE. An alginate-based hybrid system for growth factor delivery in the functional repair of large bone defects. Biomaterials. 2011; 32:65-74.

63. Ratanavaraporn J, Furuya $H$, Kohara $H$, Tabata $Y$. Synergistic effects of the dual release of stromal cell-derived factor- 1 and bone morphogenetic protein-2 from hydrogels on bone regeneration. Biomaterials. 2011; 32:2797-811

64. Van Lenthe GH, Hagenmüller H, Bohner M, Hollister SJ, Meinel L, Müller R. Nondestructive micro-computed tomography for biological imaging and quantification of scaffold-bone interaction in vivo. Biomaterials. 2007; 28:2479-90.

65. Saito E, Liao EE, Hu W-W, Krebsbach PH, Hollister SJ. Effects of designed PLLA and 50:50 PLGA scaffold architectures on bone formation in vivo. J Tissue Eng Regen Med. 2013; 7:99-111.

66. Boerckel JD, Kolambkar YM, Dupont KM, Uhrig BA, Phelps EA, Stevens HY, García AJ, Guldberg RE. Effects of protein dose and delivery system on BMP-mediated bone regeneration. Biomaterials. 2011; 32:5241-51

67. Bowman W. On the structure and use of the malpighian bodies of the kidney, with observations on the circulation through that gland. Philos Trans R Soc London. 1842; 132:57-80.

68. Beeuwkes $\mathrm{R}$, Bonventre JV. Tubular organization and vascular-tubular relations in the dog kidney. Am J Physiol. 1975; 229:695-713.

69. Garcia-Sanz A, Rodriguez-Barbero A, Bentley MD, Ritman EL, Romero JC. Three-dimensional microcomputed tomography of renal vasculature in rats. Hypertension. 1998; 31:440-4

70. Duvall CL, Taylor WR, Weiss D, Guldberg RE. Quantitative microcomputed tomography analysis of collateral vessel development after ischemic injury. Am J Physiol Heart Circ Physiol. 2004; 287:H302-10.

71. Boerckel JD, Chandrasekharan UM, Waitkus MS, Tillmaand EG, Bartlett R, DiCorleto PE. Mitogen-activated protein kinase phosphatase-1 promotes neovascularization and angiogenic gene expression. Arterioscler Thromb Vasc Biol. 2014; 34:1020-31

72. Phelps EA, Landázuri N, Thulé PM, Taylor WR, García AJ. Bioartificial matrices for therapeutic vascularization. Proc Natl Acad Sci U S A. 2010; 107:3323-8.

73. Savai R, Langheinrich AC, Schermuly RT, Pullamsetti SS, Dumitrascu R, Traupe H, Rau WS, Seeger W, Grimminger F, Banat GA. Evaluation of angiogenesis using micro-computed tomography in a xenograft mouse model of lung cancer. Neoplasia. 2009; 11:48-56.

74. Missbach-Guentner J, Hunia J, Alves F. Tumor blood vessel visualization. Int J Dev Biol. 2011; 55:535-46.

75. Landázuri N, Joseph G, Guldberg RE, Taylor WR. Growth and regression of vasculature in healthy and diabetic mice after hind limb ischemia. Am J Physiol Regul Integr Comp Physiol. 2012; 303:R48-56.

76. Badea CT, Drangova M, Holdsworth DW, Johnson GA. In vivo small-animal imaging using micro-CT and digital subtraction angiography. Phys Med Biol. 2008; 53:R319-50.

77. Schambach SJ, Bag S, Schilling L, Groden C, Brockmann MA. Application of micro-CT in small animal imaging. Methods. 2010; 50:2-13.

78. Badea C, Hedlund LW, Johnson GA. Micro-CT with respiratory and cardiac gating. Med Phys. 2004; 31:3324-9.

79. Palmer AW, Guldberg RE, Levenston ME. Analysis of cartilage matrix fixed charge density and three-dimensional morphology via contrastenhanced microcomputed tomography. Proc Natl Acad Sci U S A. 2006 103:19255-60

80. Xie L, Lin AS, Kundu K, Levenston ME, Murthy N, Guldberg RE. Quantitative imaging of cartilage and bone morphology, reactive oxygen species, and vascularization in a rodent model of osteoarthritis. Arthritis Rheum. 2012; 64:1899-908.

81. Thote T, Lin AS, Raji Y, Moran S, Stevens HY, Hart M, Kamath RV, Guldberg RE, Willett NJ. Localized 3D analysis of cartilage composition and morphology in small animal models of joint degeneration. Osteoarthritis Cartilage. 2013; 21:1132-41. 
82. Willett NJ, Thote T, Lin AS, Moran S, Raji Y, Sridaran S, Stevens HY, Guldberg RE. Intra-articular injection of micronized dehydrated human amnion/ chorion membrane attenuates osteoarthritis development. Arthritis Res Ther. 2014; 16:R47.

83. Kotwal N, Li J, Sandy J, Plaas A, Sumner DR. Initial application of EPIC $-\mu C T$ to assess mouse articular cartilage morphology and composition: effects of aging and treadmill running. Osteoarthritis Cartilage. 2012; 20:887-95.

84. Lau SF, Wolschrijn CF, Siebelt M, Vernooij JC, Voorhout G, Hazewinkel HA. Assessment of articular cartilage and subchondral bone using EPICmicroCT in Labrador retrievers with incipient medial coronoid disease. Vet J. 2013; 198:116-21.

85. Kok AC, Tuijthof GJ, den Dunnen S, van Tiel J, Siebelt M, Everts V, van Dijk $\mathrm{CN}$, Kerkhoffs GM. No effect of hole geometry in microfracture for talar osteochondral defects. Clin Orthop Relat Res. 2013; 471:3653-62.

86. Renders GA, Mulder L, Lin AS, Langenbach GE, Koolstra JH, Guldberg RE, Everts V. Contrast-enhanced microCT (EPIC- $\mu$ CT) ex vivo applied to the mouse and human jaw joint. Dentomaxillofac Radiol. 2014; 43:20130098.

87. Piscaer TM, Waarsing JH, Kops N, Pavljasevic P, Verhaar JA, van Osch GJ, Weinans $\mathrm{H}$. In vivo imaging of cartilage degeneration using microCTarthrography. Osteoarthritis Cartilage. 2008; 16:1011-7.

88. Siebelt M, Waarsing JH, Kops N, Piscaer TM, Verhaar JA, Oei EH, Weinans $H$. Quantifying osteoarthritic cartilage changes accurately using in vivo microCT arthrography in three etiologically distinct rat models. J Orthop Res. 2011; 29:1788-94.

89. He P, Yu H, Bennett J, Ronaldson P, Zainon R, Butler A, Butler P, Wei B, Wang G. Energy-discriminative performance of a spectral micro-CT system. J Xray Sci Technol. 2013; 21:335-45.

90. Alvarez RE, Macovski A. Energy-selective reconstructions in X-ray computerized tomography. Phys Med Biol. 1976; 21:733-44.

91. Nuzzo S, Peyrin F, Cloetens P, Baruchel J, Boivin G. Quantification of the degree of mineralization of bone in three dimensions using synchrotron radiation microtomography. Med Phys. 2002; 29:2672-81.

92. Anderson NG, Butler AP. Clinical applications of spectral molecular imaging: potential and challenges. Contrast Media Mol Imaging. 2014;9:3-12.

93. Granton PV, Pollmann SI, Ford NL, Drangova M, Holdsworth DW. Implementation of dual- and triple-energy cone-beam micro-CT for postreconstruction material decomposition. Med Phys. 2008: 35:5030.

94. Clark DP, Badea CT. Micro-CT of rodents: state-of-the-art and future perspectives. Phys Med. 2014; 30:619-34.

95. Ritman EL. Current status of developments and applications of micro-CT. Annu Rev Biomed Eng. 2011; 13:531-52.

96. Tapfer A, Bech M, Velroyen A, Meiser J, Mohr J, Walter M, Schulz J, Pauwels B, Bruyndonckx P, Liu X, Sasov A, Pfeiffer F. Experimental results from a preclinical X-ray phase-contrast CT scanner. Proc Natl Acad Sci U S A. 2012; 109:15691-6.

97. Tapfer A, Braren R, Bech M, Willner M, Zanette I, Weitkamp T, Trajkovic-Arsic M, Siveke JT, Settles M, Aichler M, Walch A, Pfeiffer F. X-ray phase-contrast CT of a pancreatic ductal adenocarcinoma mouse model. PLoS One. 2013; 8:e58439.

doi:10.1186/scrt534

Cite this article as: Boerckel et al:: Microcomputed tomography: approaches and applications in bioengineering. Stem Cell Research \& Therapy 2014 5:144 